\title{
Challenges Which Hinder Citizen Participation in Governance Affairs in Nalusanga Zone, Mumbwa District, Zambia
}

\author{
Andrew Nswana and Eunifridah Simuyaba* \\ The University of Zambia \\ *Corresponding author
}

\begin{abstract}
This study explored the challenges which hinder citizen participation in governance issues in Nalusanga Zone of Mumbwa District. The major aim of the study was to establish the challenges which hindered citizen participation in governance processes with a view to inform policy direction. A qualitative research approach, anchored on an exploratory research design, was applied to achieve the research purpose. Interview guides and focus group discussions were used as research instruments to explore the research problem on purposively selected individuals. Data which was analysed thematically, revealed recurring themes from the data. The study revealed that citizens faced a number of challenges in governance participation. These included; ignorance, poor distribution of resources, poverty, illiteracy, having ineffective participatory systems and platforms which influenced the participation of the citizens in public governance.Upon establishing a number of challenges that citizens faced in governance affairs, the study made a number of recommendation to counter the stated challenges. Among the main recommendation were the need for the government to provide empowerment funds to the area in order to reduce poverty levels. The need to sensitise members of the public about the importance of citizen participation in national affairs was also recommended. The government was to develop platforms for public participation which are relevant, coordinated and accessible in order for the public to participate in governance and development in a meaningful manner. Finally, there was need to create interactive public consultations in order to improve the quality of participation.
\end{abstract}

Key words: challenges, citizen, participation, governance, Zambia.

\section{INTRODUCTION}

$\mathrm{T}$ his study is an extract from the lead researcher's master's dissertation pursued at the University of Zambia. The study concentrated on the challenges which hinder citizens' participation in Nalusanga zone in Mumbwa district. According to Hirst and Pierre (2000), implementation of the public participation process is important for the democratisation of social values and better planning and fulfillment of public needs. It is also useful for educating the public, especially regarding government development programmes. This will potentially influence social or personal changes amongst community members, which can then be used to incorporate diverse public interests and thus accord people the right to participate in decisions that will affect their lives.
According to Slocum and Thomas-Slayter (1995), public participation is a means to convey individual and the society's personal interests and concerns with regard to the development plans, given that these planning activities would consequently affect the public generally and certain groups specifically. Chadwick (1971), contends that when citizens participate in the decision-making process, the public will realize the importance of their involvement in deciding their future.

Ever since Zambia gained its independence in 1964, there has been an emphasis by different stakeholders to encourage citizens to take part in the affairs of the nation(Falconer-stout, Kalimaposo \& Simuyaba (2014). This is because of the fact that every citizen in the country has a responsibility and a duty to participate in running the affairs of the nation as enshrined in the national constitution of Zambia (constitution of Zambia, 1996) and in the National Decentralization Policy of 2002. The decentralization policy was introduced to enable grass root participation among stakeholders in governance of affairs in various ministries.

\subsection{Background of the Study}

In recent years, citizens in many countries have been on the receiving end of a wave of interest from Governments, NGOs, donors and lenders in ways of involving them more actively in shaping decisions that affect their lives. Forms of political participation associated with liberal democracy have come to be complemented with a new architecture of democratic practice. These moves have given rise to new interactions and institutions, blurring old boundaries and creating new configurations of power and resistance.

In Bardhan (2002)'s view, citizen participation in governance and public service delivery is increasingly pursued in a bid to improve the performance of governments. Indeed, improving delivery of public services continues to be a key objective that has occupied the agenda of public administrators and researchers. Faced with constraints and failures of centralised service delivery systems, especially at the local level, governments have turned to decentralised mechanisms of service delivery. Further, public participation stimulates information exchange between all the proposed development's stakeholders such as the public, government 
and non-government organizations which will further enhance the mutual understanding and relationship between the stakeholders and resulting in the government and the proposed development enjoying instilled support (Glass, 1979; Cavric, 2011).

From the public's perspective, the act of inviting citizens to engage in the decision-making process is considered as a sign of acceptance by the government. The public is affected by the related development plan or proposal, and is within the public's interest to allow participation in the decision-making process, from the early stage of related planning procedure. This is because this will encourage citizens' input in the planning process and present the views of the entire community on specific issues to ensure the proposed plan mirrors their aspirations. In a broader sense, appropriate public participation is the key towards sustainable development given that the proposed development will be structured based on the stakeholders' demands and needs, which include the benefits for future generations (Azfar, et al., 1999). However, at the heart of this matter rests the issue of conditions that might constrain achieving appropriate public participation. It is assumed that public participation efficiency and effectiveness might be compromised by the difficulties faced by the public when it comes to understanding the technical reports and the complex planning issues (Jenkins, 1993;Masaitiand Simuyaba(2018). This will consequently affect the public's ability to comprehend the decision-making process. According to Bramwell and Sharman (1999), effective public participation is difficult to achieve if the residents are not equally represented within or when they are not part of the whole group of stakeholders. This lack of participation in Governance has been cited by Zambian Scholars like Kandondo, 2010,Falconer-stout, Kalimaposo \& Simuyaba (2014) Nswana, 2021) and has remained a problem in Zambia.With this background, the researchers investigated the nature of challenges that hindered citizen participation in governance affairs in Mumbwa district?

\subsection{Statement of the Problem}

In Zambia, the challenge confronting the nature of citizen participation has been that of mandatory citizen participation in governance affairs at every level of government by every citizen including those in rural areas as enshrined in the Constitution of Zambia which is the highest law of the land (The Constitution of the Republic of Zambia (Cap 1 of 1996 of the Laws of Zambia). This is because Citizen Participation is every citizen's responsibility in a democratic country like Zambia. However, what had not been known were the challenges which hindered citizen participation in governance affairs of the country in Nalunsanga Zone, Mumbwa District, Zambia.

\subsection{Purpose of the study}

The purpose of study was to explore the challenges which hindered citizen participation in governance affairs in Nalunsanga Zone, Mumbwa District.

\subsection{Theoretical framework.}

The study applied two theories:

\subsubsection{Public Choice Theory}

The Public Choice Theory (PCT)'s main attention is on how people make choices in their bid to choose on public services. It equates public service delivery to a market-like competition(Savas 2002). This theory therefore, is used in this context to explain the position of public participation in governance in Zambia in general and in Mumbwa district in particular, with a view to ensure effective delivery of public goods and services through citizen participation in governance affairs.

\subsubsection{Public Value Theory (PVT)}

Public value theory assumes that services are provided in line with the public interest (Bozeman 2002). Public interest can be explained as the choice knowledgeable citizens will make for the best interest of the society. This theory may be used to explain the benefits which the citizens in Mumbwa district will reap by being enlightened to participate in governance and allowed to make the best choices for the benefit of the whole community, (Bozeman 2002, and Lippman 1955).

Presently, all efforts and attempts are planned and directed towards achieving the best public interests, unlike in the past where public interest was not defined or planned for. In instances where public interest was not clearly defined or planned for, it was conflicting with other community policies, (Staples andDalrymple 2008; Stoker 2006). This recognition of embracing people's interests in governance has had positive impacts, especially to the citizens. This therefore justifies the selection of the two theories which are linked to participation of citizen in governance; our central focus of the study.

\section{LITERATURE REVIEW}

\subsection{Challenges which hinders public participation}

Hashim (1986), highlighted that the main purpose of public participation is to offer the public an opportunity to participate in the decision-making process of related development planning. In the context of this study, related development planning refers to a stakeholder engagement with any development plan that might affect citizens physically, mentally or both. However, the success of the process depends on how far the public is allowed to be involved (Hashim, 1986 and Lukic, 2011).

Woodley (1999), also documented a negative impact of an inappropriate and unequal public participation or involvement due to prioritisation of power of involvement to stakeholders with a particular interest. Plainly stated, the power of involvement was limitedly enabled to the remaining stakeholders, which led to local community members' dissatisfaction towards a proposed development which resulted in failure to achieve the local community's support. 
A study done by Timothy (1999), established that public participation in the decision making process in Yogyakarta city, of Indonesia is literally non-existent. The same study reported a negative feedback from the local community with regards to their rights to be involved in public participation where it is claimed that public involvement was neither practiced nor implemented, in any official development plans in Yogyakarta. Also and more importantly, the local community had not been clearly informed of their rights to public participation (see also Keogh, 1990). Consequently, the local community had not participated in the decision-making process of any proposed developments and the absolute power to decide was handed to the government.

According to another perspective, public participation could also lead to better policy formulation and implementation and can thus be associated with a greater attainment of public programmes' goals (Beierle\&Cayford, 2002; Fagotto\& Fung, 2009; Fung, 2004 and Falconer-stout, et.al, 2014 andMwase and Simuyaba, et.al 2020). Moynihan (2003) links participation benefits to the performance of public programmes. Public input can provide information that helps managers improve public efficiency. That is either allocative efficiency through better resource allocation choices or managerial efficiency through information that leads to improvement of the process of public service provision.

Studies from India and Turkey indicated that the legal structures have placed a barrier between the resident and the local authority (Tosun, 1998). The stakeholders have no access at all to the consultation process (Few, 2000). Tosun (1998), further indicated that the centralised administration system failed to prioritise local residents' participation in development planning. It was established that in centralised governments, often there existed administrative bureaucracies which breeds inefficiencies especially in the length of time taken to make and implement a decision, the chances of poor utilisation of public funds was high with a lot of funds going into corrupt official's pockets, and the exclusion in the development processes of the less loud and lacking influence persons in the community. Further, they are marred by overlaps, duplication of functions and poor or no plans to involve the citizens' contribution (Fung, A. \& Wright, 2001).

Furthermore, World Bank (2002), Falconer-stout, et.al, 2014and Mwase\& Simuyaba, et.al, 2020) argued that some citizens' faces communication problems, illiteracy and ignorance challenge to public participation. Important government manuals are documented mainly in the language which majorities do not understand. However, the majority of the masses are semi-literate (Kabungo, 2020). Additionally, access to radio and other print and electronic media is limited to a section of the citizenry mainly the elite and the urban dwellers. This prevents a majority of the citizens from participating in governance (Nswana, 2021).

Political interference is also a challenge to citizen participation in many societies. Politicians were found to be keen on achieving individual and partisan agenda. They usually distort the content and aim of public participation was tuned to suit their needs. Consequently, instead of the public giving objective and well informed input and suggestions, they end up playing into the hands of political machinations and plans. Some government officers complained that politicians, often interfere with their work as they seek to push for projects that they consider to be "politically valuable". Data on citizen participation, let alone challenges of citizens in participation in governance remains a matter for conjuncture. This study therefore, sought to fill this gap.

\section{METHODOLOGY}

This study was qualitative in nature and employed a qualitative approach. Burns and Grove (2003:19), Kombo and Tromp (2006) and Njobvu and Simuyaba (2020) describe a qualitative approach as "a systematic subjective approach used to describe life experiences and situations to give them meaning". Further,exploratory research design was adopted for this study. Exploratory research according to Kothari (2003); Yin (2003) and Kapembwa and Simuyaba, et;al (2020), is used to shed light of a situation. It involves explorative studies undertaken when a new area is being investigated or when little is known about an area of interest.

\subsection{Sampling Techniques/ Procedure}

Purposive sampling technique was employed in this study. Bernard (2002), views purposive sampling as a deliberate system of choosing a participant due to the knowledge he or she has. It is a non-random technique that does not require any theory or a set of informants.

\subsection{Data Collection tools}

In-depth interview guides, focus group discussions and semistructured interview guides were used to collect data from five councilors, ten ordinary citizens and five traditional leaders in Nalusanga Zone in Mumbwa District.

\subsection{Data Analysis}

Qualitative data was analysed using common themes that emerged from the research findings. A theme is defined as a main idea or an underlying meaning of a literary work that may be stated directly or indirectly(Creswell, 2008). Data from focus group discussion and in-depth interviews was transcribed and was presented as verbatim from the audio record. The data was then analysed manually; based on recurrent themes and patterns and categorised using codes in line with the research objectives.

\subsection{Trustworthiness}

To ensure trustworthiness in this study, various strategies were constantly applied, including credibility, transferability, dependability and conformability. This was in line with the principles of qualitative research as held by Lincoln and Guba (2003). 


\section{FINDINGS AND DISCUSSION}

\subsection{Findings.}

Findings for this study are presented according to the subcategories formulated in relation to theobjectives and the emerging themes. Challenges which hinder citizen participation in governance issues are categorized into themes as highlighted below:

\subsubsection{Individual challenges.}

The findings showed that poverty was one of the individual challenges citizens face in Nalusanga Zone. During the interview, one participant had the following to comment regarding poverty:

\section{Poverty is one of the challenges hindering us from participating in governance issues because we lack resources to generate money for transport to travel to where meetings are being held, and moreover we 'live from hand to mouth' which requires working for food every day.}

It is clear from the above narrative that some citizens from Nalusanga Zone had problems of limited resources which hindered them from participating in governance issues. Furthermore, it was also found that communication barrier was another individual challenge which hindered citizen participation in governance. One participant said the following on this subject:

Yes, communication in many ways hinders many people from participating in governance issues, for example, when [us] citizens are called to attend many of the forums, we are required to express ourselves in English which we are not conversant or confident in expressing ourselves in. Moreover most of the documents are written in English which not all can read and comprehend, thus they opt not to attend.

It was further established that limited technology advancement had hindered citizen participation in governance issues, especially with the outbreak of Corona virus pandemic which made citizens to attend virtual meetings using mobile phones. A female participant had the following remarks:

Use of virtual meetings as a way of having meetings due to Covid-19 has affected us from participating in governance issues when there is a meeting in the zone because some of us do not have smart phones to use, and even those with smart phones may not afford to buy bundles for internet. So this has affected the already limited citizen participation in governance in the area.

Furthermore, another participant in a Focus Group Discussion (FGD) pointed out another challenge hindering citizens from participation in governance when seminars were conducted during the weekdays when majority of the citizens are in the places of work. Only a few people can find a gap in their busy schedules to attend. This was reflected in the following remarks:

Challenges are many, for example some
interested individuals who are working classes
are disadvantaged in our zone because
sometimes, when there is a seminar, it is
conducted during working days and this hinders
them from participating in the seminars to
discuss governance issues.

The above narratives highlighted some individual barriers to participation in governance issues. However, there were some socio-cultural challenges as well. The following section presents findings on some socio-culture challenges that affected the citizens of Nalusanga Zone in attending governance meetings.

\subsubsection{Socio-cultural challenges}

The study found that married women in Nalusanga Zone were facing challenges of not being allowed by their husbands to attend governance programmes. One of the female participants said the following:

Most of us women who are married and not
formally employed have to seek permission and
funding from our husbands to attend any
meeting whether political, social or economic
in nature. Furthermore, most of these meetings
and government forums are conducted in
English which we understand but are unable to
speak fluently. This makes us to shy away. If a
forum has financial benefit, the leaders and
organizers only inform and invite their family
members, friends and their political supporters.

It is clear from the above finding that gender disparity between the female and male folks was one of the barriers to participation in governance issues. The female gender was disadvantaged in as far as participation was concerned. One female participant had the following to say;
Yes, men like pulling women down. They like leaving women behind many developmental programmes, for example, in my case I only attend the meetings approved by the husband. Sometimes, my husband tells me that it's a waste of time which could be used doing other beneficial chores for the family. I really wish to participate but I am not allowed!

The study also discovered that a good number of citizens were not aware about their civic duties. Further, majority of the citizen in the area are not educated and this resulted into high rate of ignorance about their roles and duties as good citizens. One participant had the following to say:

I think the biggest challenge the villagers have pertaining to citizen participation is limited knowledge about their civic duties, obligations 
and responsibilities. Some of the people in these areas are not aware about their roles and duties as citizens. In addition to ignorance, there is also high prevalence of levels of illiteracy amongst many rural dwellers. For the few who attended school, I think they have not been orientated to engage themselves in national or local development issues.

The socio-cultural challenges, which were highlighted by the participants, were gender disparity in meetings, males not allowing wives in participation in governance, and high level of illiteracy among citizens in Nalusanga zone. These were said to be barriers in participation in governance issues at this level. The study, however, unearthed some general challenges as well. These are highlighted below:

\subsubsection{General challenges}

Under the general challenges, the study established that corruption was affecting citizens from participating in the public affairs. One participant had this to say:

There is too much corruption among the people in leadership. Corruption levels and its great negative effect to the participation of citizens in governance has hindered majority of citizen from participating. This ranges from misappropriation of funds, nepotism to favoritism in development of some areas. The corrupt activities discourage us from participating in government meetings because other receive some favours which we don't seem to benefit from.

Furthermore, the findings showed that the majority of the people in the area were ignorant of their duties and responsibilities as citizens. When probed about the levels of participation that they knew, they only pointed out that they voted. One participant had the following remarks:

Governance participation...well, there is not much that we know as a community. All what we know is just voting for members of Parliament and Councilors that represent in us in Lusaka. Basically, participation ends at the level of voting and attending political rallies.

Furthermore, the study found that there were no clear channels of communication between citizens and duty bearers and if there was any, it was of a weak and defunct kind and hence, in many instances, it disadvantaged local citizens to provide effective accountability actions on public servants.

Besides, there were very limited and fragile accountability platforms to facilitate citizens' participation, especially in rural areas as compared to urban areas where there were many platforms for citizen to voice out. One participant's remarks were that:
We are lagging behind in providing checks and balance and demanding good governance due to lack of clear and strong platforms for participatory governance. What I can say is that most citizens are not aware of the platforms for participation in governance.

This view was echoed by another participant, who explained that the government was not doing much in terms of expanding social amenities. For example, the radio stations that communities owned, were just but local, which could cover very few miles in terms transmission:

We are lagging behind here in terms of
platforms for citizen participation, there are
no amenities like radio talk show, writing to
the print media especially through letters to
the editors has provided an opportunity for
citizens to exercise their right to be heard
and participate in the development
processes

The individuals, socio-cultural and general challenges given by the participants have been highlighted. These are said to have hindered citizen participation in governance.

\subsection{Discussion of the findings}

The challenges which hinder citizen participation in governance participation existed in many forms in Nalusanga zone of Mumbwa district. According to this research, majority of people in the area were still ignorant of their rights and the responsibility to participate in the development and governance processes. This view resonates well with the views of John John (2009), UN John (2008), and Yang and Callahan John (2007), According to John (2009); UN (2008); and Yang \& Callahan (2007)'s studies, low literacy levels was a challenge facing citizen from participation in governance affairs. Furthermore, cultural practices coupled with low levels of literacy inhibit equal and open participation from ordinary citizens in that, procedures do not enable them to directly address their traditional leadership unless required to do so by the traditional authorities.

Further, this study found the following individual challenges; poverty, insecurity and disinterest, communication barriers, lack of confidence to participate in the development discussions and national debates of the country, lack of sufficient time to attend seminars due to the fact that seminars are conducted during working days when most of people were at work.

Furthermore, it was found that there were very limited opportunities for citizens' participation through the government structures, and this was influenced by existing structural and systemic arrangements based on the manner in which the bureaucracy operates. Similar structural and bureaucratic barriers were found in earlier studies. For example, according to Anwar (2007)'s study, citizens found it 
difficult to participate in governance issues because people in leadership invited the public for public participation forums without giving them enough information and necessary documents in time. This action had resulted in few people turning up for meetings and even those who turned up were not able to ask questions or make adequate contributions because they were getting information for the first time.

The study further established that political inclinations influenced the extent and quality of public participation, and that when citizens participated, they were not motivated because their views were not always taken into consideration. This resonates well with Dinham (2005) and Timothy (1999)'s studies in other contexts where it was also established that not everyone's views are taken into consideration when citizens participated the United Kingdom's new deal community activities. The difference here lies in contextual arrangements.

The study further established that public participation seemed to be much more facilitated at the national level, than at a local level, thereby making it difficult for those located in outlying rural areas to participate and influence public policy. The citizens in Mumbwa district indicated that they lacked some platforms which facilitated citizens' participation especially in the rural areas as compared to urban areas where there were many platforms for citizen participation, including social or digital media. In addition, there were no varieties of participatory platforms like radio talk shows, writing to the print media especially through letters to the editors, which could have provided an opportunity for citizens to exercise their right to be heard and participate in national development. This finding is not unique to Mumbwa district. Earlier studies like one byWales, Yang and Pandey (2011) had similar findings. In Wales, Young and Pandey's (2011) study participation was inhibited by limited varieties of platforms to participate in governance issues. Though done in a different context, their findings are similar to those in Mumbwa rural district.

The study further established that the majority of the citizens in the rural areas did not understand their civic roles and responsibilities as citizens tended to think that their role ended with elections. The open life after election was none of their business and hence they left everything to their elected leaders. Besides, most of the citizens did not know the responsibilities of their leaders, as a result they were not able to hold them accountable. This finding resonates well with Mncube's (2008) and Falconer-stout, Kalimaposo \& Simuyaba (2014) and Simuyaba and Chibwe's (2015) studies which established that parental participation in governance was inhibited by lack of understanding of their roles in governance issues. Mncube's (2008) study for example, observed that this lack of participation was attributed to the parents' low literacy levels in education policies. Similarly, the citizens of Nalusanga zone were in a rural set up and hence the majority of the people lacked the continuous engagement between the elected leaders and themselves, mainly because of lack of information on the levels at which they could engage their elected leaders.

Furthermore, the study revealed that there were no clear channels of communication between citizens and duty bearers, and if there was any, it was weak and defunct and so, in many instances this disadvantaged local citizens to provide effective accountability actions on public servants. Besides, it was established in this study that there were very limited and fragile accountability platforms to facilitate citizens' participation, especially in rural areas as compared to urban areas where there were many platforms for citizen to voice out. One respondent's remarks were that; they are lagging behind in providing checks and balances and in demanding good governance due to lack of clear and strong platforms for the participation in governance issues. It was thus concluded that the government was not doing much in terms of expanding social amenities which could facilitate participation. For example, the radio stations that communities own, in Central Province where Mumbwa district lies and indeed other rural districts, were just but local, and these only covered very few miles in terms of transmission, thereby leaving the rest of the population not adequately reached by modern trends of civic engagement in public affairs.

\section{CONCLUSION AND RECOMMENDATIONS}

In conclusion, the study revealed that there were numerous challenges which hindered citizens from participating in governance affairs in Nalusanga Zone based in Mumbwa District. The identified challenges included lack of platforms to facilitate citizens' participation, poor distribution of resources, ignorance caused by illiteracy about their duties and responsibilities as citizens to participate in national or governance matters and debates, lacking formal procedures to host public views and lack of proper channels and mechanisms for feedback and accommodation of public inputs. Further, communication barriers, high illiteracy levels and lack of confidence among ordinary members and their own local leadership and gender disparities among community members were found to be disablers for citizen participation in governance. Other barriers to active participation were attributed to lack of participatory incentives among citizens because they felt that voting was adequate participation in governance affairs in the country and that there was nothing much to get beyond voting for their leaders.

\subsection{Recommendations}

Drawing from the findings of the study, which focused on the challenges citizens face in participating in governance affairs in Nalusanga Zone, in Mumbwa District, the following suggestions were made:

i. The government to provide empowerment funds to the people in the area in order to reduce poverty levels which was one of the main barriers to active participation in governance.

ii. Sensitise citizens about the importance of citizen participation in national affairs. This would 
encourage their participation in governance because they would know the importance of participation and ways in which they could participate.

iii. Develop platforms for public participation which were relevant, coordinated and accessible in order for the public to participate in governance and development in a meaningful manner. This would improve accountability and transparency in development and economic processes and eventual would enable rights holders and duty bearers to engage in constructive dialogue and joint action planning in the affairs district.

iv. Create interactive public consultations and democratic representation, and transparency in order to improve the quality of participation through a decentralized system.

v. Create interactive public consultation forums such as community radio stations, consultative meetings with the rural populations and boost phone networks in order to improve the quality of participation in the rural zones.

\section{REFERENCES}

[1] Blair, H. (2000), 'Participation and Accountability at the Periphery: Democratic Local Governance in Six Countries', World Development, vol. 28, no. 1.

[2] Box, R. (1998). Citizen governance: Leading American communities into the 21st century. Thousand Oaks, CA: Sage Publication.

[3] Creswell, J.W. (2008). Educational research: Planning, conducting, and evaluating quantitative and qualitative research. Third edition. Upper Saddle River, NJ: Pearson.

[4] Cuthill, M. (2002). 'Exploratory research: citizen participation, local government and sustainable development in Australia'. Sustainable Development, 10: 79-89.

[5] Devas, N., and Grant, U. (2003). Local government decision making - citizen participation and local accountability: Some evidence from Kenya and Uganda. Public Administration and Development, 23, 307-316.

[6] Dinham, A. (2005). Empowered or over-powered? The real experiences of local participation in the UK's new deal for communities. Community Development Journal, 40(3), 301-312.

[7] Dhungel, D. N. (2004). Decentralized governance: A perspective for Nepal. Paper presented at the Seminar on Reforming Governance-Perspectives and Experience in Bangalore, India. Retrieved September 5, 2011 from http://iids.org.np/project test/wp-content/uploads/2014/08/dn2.pdf

[8] Falconer-Stout, Z.J; Kalimaposo, K and Simuyaba, E. (2014) 'The Role of Active Parent Community School Committees in Achieving Strong Relative School Performance in Zambian Community Schools'. Southern Africa Review of Education. Available on https://encompassworld.com/resource/the-role-of- active-parent-community-school-committees-in-achieving-strongrelative-school-performance-in-zambian-community-schools/

[9] Glass, J. (1979). Citizen Participation in Planning: The Relationship between Objectives and Techniques. Journal of the American Planning Association, 45: 180-189.

[10] Hartley, N. \& Wood, C. (2005). Public Participation in Environmental Impact Assessment: Implementing the Aarhus Convention. Environmental Impact Assessment Review, 25: 319340.

[11] Hirst, P \& Pierre J. (2000). Democracy and Governance, Debating Governance', Oxford University Press, Oxford.

[12] Kapembwa, R, Simuyaba, E, Njobvu, T, Muleya, G and Simui, F (2020) 'School Based Restorative Practices in Influencing Positive Behaviour in Deviant Pupils in Zambia'. International Journal of Education and Research. Vol.8, 12, 93-110. Available on http://www.ijern.com/journal/2020/December-2020/09.pdf

[13] Kombo, D.K and Tromp, D.A. (2006). Proposal and Thesis Writing: An introduction. Nairobi: Paulines Publications Africa.

[14] Lichfield, N. (1996). Community Impact Evaluation. London: UCL Press.

[15] Masaiti G. and Simuyaba E. (2018). 'University Education in Zambia in the Face of Austerity: History, Trends and Financing' in Education in Zambia at Fifty years of Independence and beyond. Lusaka: Unza press. Also available on https://www.researchgate.net/publication/

[16] Mncube, V. (2008) 'The Perception of Parents of their Role in Democratic Governance of Schools in South Africa: Are they on Board'? South African Journal of Education. Vol.20. 83-103.

[17] Mwase, D; Simuyaba, E; Mwewa, G; Muleya, M and Simui, F. (2020) 'Leveraging Parental Involvement in the Education of their Children as a Conflict Resolution Strategy in Selected Secondary Schools in Zambia'. International Journal of Research and Innovation in Social Science. Vol.1.No.7. July 2020, Pp 356-365.

[18] Njobvu T and Simuyaba, E. 'Pupil Indiscipline in the No Corporal Punishment Era IN Zambia: Trends and Implication for Management in Schools'. Zambia Journal of Education Management, Administration and Leadership. Vol 1, no 1. 179192. Available also on https://education.unza.zm/index.php/ZJEMAL/article/download/2 $\underline{21 / 201}$

[19] Nswana A, ( 2021) 'Exploring the Nature And Extent of Citizen Participation In Governance In Nalusanga Zone, Mumbwa District' Unpublished Dissertation Submitted to The University of Zambia in Association with Zimbabwe Open Universityin Partial Fulfilment of theRequirement for the Award of Master of Science in Peace, Leadership and Conflict Resolution. Lusaka.

[20] Simuyaba, E; Banda, D; Mweemba, L and Muleya G. (2015) 'Theory Against Practice: Training of Teachers in a Vacuum'. Journal of Education and Social Policy. Vol2, no.5. Pp 88-96.

[21] Simuyaba, E \&Chibwe, P. (2016) 'Teacher Professionalism in Zambia: Practices, Challenges and Prospects in the Post 2015 Era'. Proceedings of the $67^{\text {th }}$ IIER International Conference, Stockholm, Sweden. Available on https://docplayer.net/63587801Teacher-professionalism-in-zambia-practices-challenges-andprospects-in-the-post-2015-era.html

[22] Smith, B. L. (2003). 'Public policy and public participation: engaging citizens and community in the development of public policy'. Population and Public Health Branch, Atlantic Regional Office, Health Canada. 